\title{
A Multi-Criteria Decision Making Approach for Enhancing University Accreditation Process
}

\author{
Nezha Benmoussa \\ Signals, Distributed Systems and Artificial Intelligence \\ Laboratory, ENSET Mohammedia, University of Hassan II, \\ Mohammedia, Morocco \\ nbnezhabenmoussa@gmail.com
}

\author{
Abir Elyamami \\ Signals, Distributed Systems and Artificial Intelligence \\ Laboratory, ENSET Mohammedia, University of Hassan II, \\ Mohammedia, Morocco \\ abir.elyamami@gmail.com
}

\author{
Khalifa Mansouri \\ Signals, Distributed Systems and \\ Artificial Intelligence Laboratory, \\ ENSET Mohammedia, University of \\ Hassan II, Mohammedia, Morocco \\ khmansouri@gmail.com
}

\author{
Mohammed Qbadou \\ Signals, Distributed Systems and \\ Artificial Intelligence Laboratory, \\ ENSET Mohammedia, University of \\ Hassan II, Mohammedia, Morocco \\ qbmedn7@gmail.com
}

\author{
Elhoussein Illoussamen \\ Signals, Distributed Systems and \\ Artificial Intelligence Laboratory, \\ ENSET Mohammedia, University of \\ Hassan II, Mohammedia, Morocco \\ Illous@hotmail.com
}

\begin{abstract}
This paper is an attempt to provide an accreditation training process model by the criteria established by the National Agency for Evaluation and Quality Assurance of Higher Education and Training. The aim is to minimize rejection returns or revisions of the training record. The main feature of our contribution is the use of multi-criteria decision making (MCDM) approaches for calculating the suitability of proposed courses. Therefore, our contribution will is concretized by the analysis of various decision support multi-criteria methods, the modeling of the general accreditation process of university courses, the development of a risk management matrix concerning the launch of new courses and the application of TOPSIS (technique for order of preference by similarity to ideal solution) on a sample of courses according to internal and external criteria, collected during interviews in Moroccan universities. Result analysis shows that the proposed model allows a better prioritization of training and thus avoids the abrupt closure of courses because of lack of material or human resources.
\end{abstract}

Keywords- decision support; MCDM; accreditation; risk management matrix; TOPSIS

\section{INTRODUCTION}

Decision-making generates very important industrial and economic issues affecting management and competitiveness of organizations. Prioritizing and optimizing all actions are two key factors of effective decision-making. Universities face the challenge of resources and investment optimization to avoid any negative impact on the management of training projects and their performance. They are always looking for innovation so that they may be able to meet the needs of the market and to encourage scientific research. All interviewed managers assume that taking an effective decision in advance, requires a preliminary study of any educational proposal. Multi-criteria decision making (MCDM) methods, are increasingly used in various fields like natural resource management, environment and spatial planning, making possible to rely on science while taking managerial decisions and to drive decision-making processes in organized systems [1]. Whether strategic, global, operational or local, decision making is generally made to manage organizations consistently: quantitatively (number of products or services offered), and qualitatively (development of standards, establishment of a charter). Therefore, making a decision requires different alternatives that must be evaluated according to one or more criteria in order to determine the optimum [2]. These alternatives and indicators help enormously in decision-making and are a great contribution to the evolution of future steps to take.

Decision support is a scientific approach to decisionmaking problems that arise in any socio-economic context in which the two main factors are the decision-maker who governs the decision-making process, and the responsible of study who intervenes at least on 1 of the 3 important levels, namely the modeling of the decision problem, the design or adaptation of a procedure for exploiting the model and the elaboration of a prescription from the solution(s) [3]. Formerly, decision support was designed to find the solution to a given problem. Today, it decently offers answers in the form of recommendations to decision-makers of a decision-making process and allows them to make better choices [4]. Operational research (OR) offers a variety of decision support tools and the most complex decisions and resource optimizations are possible through a number of algorithmic approaches that iteratively build a solution, descent heuristics that seek a global optimum from a given solution and metaheuristics that break down objectives to ease decision-making. These purely algorithmic resolution methods in the decisionmaking domain resolve in time, efficiently and quickly, to a solution or choice [5]. Indeed, OR is a discipline of scientific methods that help the making of a decision. It refers to notions

Corresponding author: N. Benmoussa 
that map our contemporary semantic and legal territory to the image of big data, e-reputation, or predictive algorithms [6]. Multicriteria decision support is a major area of study of OR involving several schools of thought, mainly American [7]. These are mathematical methods to choose the best solution or the optimal solution among a whole set of solutions.

In this paper, we contribute by analyzing various MCDM methods, modeling the general process of accrediting academic training and developing a risk management matrix for the launch of new courses and the application of TOPSIS on a sample of courses according to internal and external criteria, collected during interviews for an effective decision-making process within Moroccan universities.

\section{MCDM METHODS}

Multicriteria decision aid (DMA) was created in the 1970s. It has aroused interest through its innovative approach starting with single-criteria analysis followed by the weighting of criteria and their aggregation procedures varied in decision problems [8]. Most conventional MCDM methods use parameters derived from the decision maker's preferences. These parameters are often used for weight calculation, quantifying the importance of each criterion in the multicriteria decision process. This domain is broken down into two subdomains:

- MADM (multi-attribute decision making) for selecting the best alternative in a predetermined set of alternatives.

- MODM (multi-objective decision making) concerning the selection of the best action in a continuous or discrete decision space. Multi-objective optimization is a branch of MODM [9].

Authors in [10] specify that in a multi-criteria decision support process, the main objective is not to find a solution, but to build or create a tool considered as useful in the decisionmaking process. Since then, the MCDM methods are more and more used including MAXMIN, MAXMAX, SAW, AHP, TOPSIS, SMART and ELECTRE [11] in order to make a choice, to classify or to sort out for an effective decision making. The MCDM's progression goes through 6 steps as shown in Figure 1.

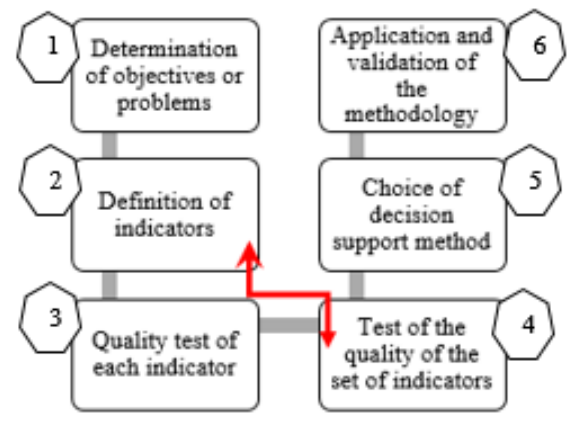

Fig. 1. General steps of MCDM methods

The test steps are important because they give an accurate assessment of the indicators. If the indicator's quality isn't conformed to the goals, it must be redefined and the test must be recommenced. Below we present some decision support methods which will be the object of a concise description specifying their functioning and their limits. TOPSIS will be more detailed since it constitutes the implementation tool of the data of our case study "accreditation and training management". The analyzed methods' advantages and limitations are shown in Table I.

\section{A. AHP (Hierarchical Process Analysis)}

AHP is a semi-quantitative method that has been developed in [12] and its computer version "Expert Choice" software was introduced in the US in 1985. It is based on the comparison of pairs of options and criteria by structuring in a logical coherence:

- Classes, criteria and hierarchical weights.

- Sub-criteria and ranks by priority.

This involves making pairs of elements of each hierarchical level with an element of the higher hierarchical level. This step makes possible to build comparison matrices. The values of these matrices are obtained by the transformation of judgments into numerical values according to the Saaty scale [13], while respecting the principle of reciprocity:

$$
P_{C}\left(E_{A}, E_{B}\right)=\frac{1}{P_{C}\left(E_{B}, E_{A}\right)}
$$

\section{B. SMART (Simple Multiple Attribute Rating Technique)}

SMART is similar to AHP, it has been developed since 1971 as a hierarchical structure created to assist in defining a problem and in organizing criteria. The difference between a value tree and a hierarchy in AHP is that the value tree has a true tree structure, allowing one attribute or sub-criterion to be connected to a higher level criterion. Its main steps are:

- Put the criteria in decreasing order of importance.

- Determine the weight of each criterion.

- Normalize the relative importance coefficients between 0 and 1: sum the importance coefficients and divide each weight by this sum.

- Measure the location of each action on each criterion $\left(u_{j}\right.$ $\left.\left(\alpha_{i}\right)\right)$. Evaluations actions are on a scale ranging from 0 (plausible minimum) to 100 (plausible maximum).

- Determine the value of each share based on the following weighted sum:

$U\left(a_{i}\right)=\sum_{j=1}^{n} \pi_{j} u_{j}\left(a_{i}\right), \mathrm{i}=1,2 \ldots \mathrm{m}$

- Classify actions in decreasing order of $U\left(\alpha_{i}\right)$.

C. TOPSIS

TOPSIS was presented in [14] and developed later in [15, 16]. It is worth noting that it corresponds to the Hellwig taxonomic method of ordering objects [17]. The main advantages of this method are: it is a simple, rational, comprehensible concept, and it has intuitive and clear logic that represents the rationale of human choice. In this method, two alternatives are hypothesized: the ideal solution that has the 
best solution for all attributes and the negative ideal solution for the one which has the worst attribute values. TOPSIS method performs prioritization of alternatives based on their geometric distance from the positive-ideal and negative-ideal solution. It reduces the need of pair comparisons and the limitation of capacity may not significantly dominate the process. Therefore, it would be appropriate for cases with a large number of criteria and alternatives, especially when objective or quantitative data are determined [18]. TOPSIS breaks down the decision into different stages:

\section{1) Formation of Decision Matrix}

Criterion outcomes of decision alternatives are collected in a decision matrix. The matrix rows represent decision alternatives, with matrix columns representing criteria. A value found at the intersection of row and column in the matrix represents a criterion outcome: a measured or predicted performance of a decision alternative on a criterion.

$$
\begin{aligned}
& \mathrm{C}_{1} \mathrm{C}_{\mathrm{j}} \mathrm{C}_{\mathrm{n}}
\end{aligned}
$$

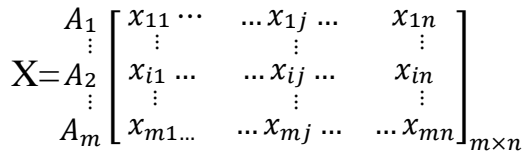

where, $x_{i j}$ is the performance rating of alternative $i$ with respect to criterion $j, A_{i}$ is $i$ th alternative and $C_{j}$ is the ${ }_{\mathrm{j}}$ th criterion.

\section{2) Formation of Weight Matrix}

Different importance weights to various criteria may be awarded by the decision maker independently or by entropy method. These importance weights form the weight matrix:

$$
\mathrm{W}=\left[\begin{array}{lllll}
W_{l} & \ldots . . W_{j} & \ldots . . W_{n}
\end{array}\right]
$$

\section{3) Normalization of Performance Rating}

Units and dimensions of performance ratings under criteria differ. For comparison, these performance ratings are converted into dimensionless units by normalization using the following equations:

$$
\bar{x}_{i j}=\frac{x_{i j}}{\max _{i}\left(x_{i j}\right)}
$$

for benefit criteria $j$ and

$$
\bar{x}_{i j}=\frac{\min _{i}\left(x_{i j}\right)}{x_{i j}}
$$

for non-benefit criteria $j$

Finally, the normalized decision matrix is formed:

$$
\bar{X}=\underset{\mathrm{A}_{\mathrm{i}}}{\mathrm{A}_{1}}\left[\begin{array}{cccc}
\overline{\mathrm{x}}_{11} \cdots & \ldots \overline{\mathrm{x}}_{1 \mathrm{j}} \ldots & \overline{\mathrm{x}}_{1 \mathrm{n}} \\
\vdots & \vdots & \vdots & \vdots \\
\mathrm{A}_{\mathrm{m}} & \overline{\mathrm{x}}_{\mathrm{i} 1} \cdots & \ldots \overline{\mathrm{x}}_{\mathrm{ij}} \ldots & \overline{\mathrm{x}}_{\mathrm{in}} \\
\vdots & \vdots & \vdots \\
\overline{\mathrm{x}}_{\mathrm{m} 1} & \overline{\mathrm{x}}_{\mathrm{mj}} & \overline{\mathrm{x}}_{\mathrm{mn}}
\end{array}\right]_{\mathrm{m} \times \mathrm{n}}
$$

4) Determination of the Positive Ideal and Negative Ideal Solution

$$
A^{+}=\left(a_{i 1}^{+}, a_{i 2}^{+}, \ldots \ldots \ldots \ldots \ldots \ldots, a_{i m}^{+}\right),
$$

$$
\begin{aligned}
& a_{i j}^{+}=\max _{1 \leq i \leq m}\left(a_{i j}\right), j=1,2 \ldots, n \\
& A^{-}=\left(a_{i 1}^{-}, a_{i 2}^{-}, \ldots \ldots \ldots \ldots \ldots, a_{i m}^{-}\right), \\
& a_{i j}^{-}=\min _{1 \leq i \leq m}\left(a_{i j}\right), j=1,2 \ldots ., n
\end{aligned}
$$

\section{5) Calculation of the Separation Measures}

Using the n-dimensional Euclidean distance the separation of each alternative from the positive ideal solution is given as:

$$
D_{i}^{+}=\sqrt{\sum_{j=1}^{n} W_{j}\left(a_{i j}^{+}-a_{i j}\right)^{2}}
$$

Similarly, the separation from the negative ideal solution is given as:

$$
D_{i}^{-}=\sqrt{\sum_{j=1}^{n} W_{j}\left(a_{i j}^{-}-a_{i j}\right)^{2}}
$$

\section{6) Step6: Calculation of the Ratio}

For each alternative, calculate the ratio $R_{i}$ as:

$$
R_{i}=\frac{D_{i}^{-}}{D_{i}^{+}+D_{i}^{-}} \mathrm{i}=1,2 \ldots \ldots \mathrm{m}
$$

7) Rank Alternatives in Increasing Order According to the Ratio Value of $R_{i}$

\section{ELECTRE I \& II}

ELECTRE I (Elimination and Choice Translating REality) was developed in 1968 and ELECTRE II in 1971 [19]. Both versions are based on the notions of concordance and discordance. ELECTRE is a non-compensatory method of multicriteria decision support. In reality, the decision maker is often undecided, his preferences evolve because the decision is the result of a process of micro decisions. The optimum can only be achieved if three conditions are met:

- The different strategies (projects) proposed to the decision maker are distinct.

- Strategies stability over time is present.

- Comparability is transitive.

E. ELECTRE III

Electre III is based on a fuzzy logic and a constructive approach which classifies actions. It favors [20]:

- Dialogue between the different factors in the decisionmaking process.

- Weighting of criteria by factors expressing preferences on resource management strategies.

- Consideration of uncertainty in the evaluation of actions by pseudo-criteria.

\section{F. ELECTRE IV}

This method assumes that all pseudo-criteria are of equal importance. It involves two outranking relations like ELECTRE II but only one set of veto thresholds and the notion of concordance is translated by a notion of majority of criteria in the absence of any weighting. 
TABLE I. MCDM METHODS: ADVANTAGES AND LIMITATIONS

\begin{tabular}{|c|c|}
\hline AHP & $\begin{array}{l}\text { Popular method that has been subjected to criticism } \\
\text { regarding the explosion of the number of pairwise } \\
\text { comparisons in case of a complex problem, the reversal of } \\
\text { rank (order of priority of the actions) in case of addition or } \\
\text { deletion and the introduction of biases by the association of } \\
\text { a numerical scale on the semantic scale which is restrictive. } \\
\text { Currently, AHP is subject to several extensions such as the } \\
\text { consideration of uncertainty (stochastic AHP) and blur } \\
\text { (fuzzy AHP) in the expression of judgments. }\end{array}$ \\
\hline SMART & $\begin{array}{l}\text { Similar to AHP and easy to exploit but requires a priori } \\
\text { articulation of preferences, and evaluation of actions on a } \\
\text { single scale (cardinal scale). It is compensatory and has } \\
\text { been developed in Criterium Decision Plus } 3.0 \text { and Decide } \\
\text { Right for automatic management. }\end{array}$ \\
\hline TOPSIS & $\begin{array}{l}\text { Easier method to apply and responsive to the decision } \\
\text { maker's wishes. However, the attributes must be cardinal in } \\
\text { nature, preferences are fixed a priori. On the other hand, if } \\
\text { all the actions are bad, the method proposes the best of } \\
\text { these bad actions. }\end{array}$ \\
\hline ELECTRE I & $\begin{array}{l}\text { It formalizes well the process of human reasoning, but has } \\
\text { the disadvantage of using quantization weights of the } \\
\text { importance of different criteria. Despite the contribution of } \\
\text { this method, the decision maker still faces the difficult task } \\
\text { of providing quantization weights. }\end{array}$ \\
\hline ELECTRE II & $\begin{array}{l}\text { It replaces the classic upgrade relationship with two new } \\
\text { relationships, namely strong upgrade and weak upgrade. }\end{array}$ \\
\hline ELECT & $\begin{array}{l}\text { It introduces the notion of pseudo-criteria that replace the } \\
\text { classical criteria. The pseudo-criteria are modeled by } \\
\text { functions whose expression is close to the membership } \\
\text { functions known in the field of fuzzy logic. }\end{array}$ \\
\hline ELECT & $\begin{array}{l}\text { Is distinguished by its ability to dispense with the weights } \\
\text { associated with each criterion. However, this benefit is } \\
\text { tempered by the need to determine a "credibility degree" } \\
\text { associated with each outranking relationship used. }\end{array}$ \\
\hline GR & $\begin{array}{l}\text { Uses a specific concept of information. It defines situations } \\
\text { with no information as black, and those with perfect } \\
\text { information as white. Neither of these idealized situations } \\
\text { ever occurs in real world problems. Situations between } \\
\text { these extremes are described as being grey, hazy or fuzzy. }\end{array}$ \\
\hline $\begin{array}{l}\text { PROMETHEE } \\
\text { GAIA }\end{array}$ & $\begin{array}{l}\text { Unlike the outranking relation constructed by the } \\
\text { ELECTRE method, which is purely binary, the relation } \\
\text { constructed by PROMETHEE is a valued upclass } \\
\text { relationship: one action outclasses another with a } \\
\text { numerical preference intensity. In 1989, GAIA provided a } \\
\text { descriptive complement to PROMETHEE rankings. Using } \\
\text { a graphical representation of the multicriteria problem, the } \\
\text { decision maker can easily understand which choices are } \\
\text { possible and which trade-offs are required to make a good } \\
\text { decision. PROMETHEE-GAIA require less } \\
\text { parameterization while remaining as efficient. It makes } \\
\text { possible to stay closer to the real decision problem, to } \\
\text { better describe it and to carry out sensitivity analyses. }\end{array}$ \\
\hline
\end{tabular}

\section{G. Gray Relational Analysis (GRA)}

Also called Deng's gray incidence analysis model [21], GRA uses a specific concept of information. It defines situations with no information as black, and those with perfect information as white. However, neither of these idealized situations ever occurs in real world problems. In fact, situations between these extremes are described as being gray or fuzzy [22]. The scope of the gray system involves agriculture, ecology, economics, meteorology, medicine, history, geography, industry, earthquake, geology, hydrology, irrigation, strategy, military affairs, sport, traffic, management, materials science, environment, biological protection, judicial system.

\section{H. PROMETHEE}

Preference ranking organization method for enrichment of evaluations (PROMETHEE) is a part of the family of upgrade methods that allow two particular mathematical treatments: partial storage (PROMETHEE I) and complete storage (PROMETHEE II). With their descriptive complement geometrical analysis for interactive aid they are better known under the names PROMETHEE and GAIA1 [23]. They are multi-criteria decision-support methods that belong to the family of methods of outreach initiated by the ELECTRE methods. PROMETHEE and GAIA methods offer a prescriptive and descriptive approach to the analysis of discrete multicriteria problems covering several areas. In fact, 217 scientific articles from 100 journals mention their fields of application on environmental management, hydrology and water management, commercial and financial management, chemistry, logistics and transport, manufacturing and assembly, energy management and other topics such as medicine, agriculture, education, design, government, and sport [24, 25].

\section{RESEARCH METHODOLOGY}

The proposed approach concerns the field of higher education in general and the Moroccan universities in particular. It meets the obligation to set up indicators before launching a new course. Indeed, the objective of this study is to contribute to the optimization of resources and especially the evaluation of existing training as well as the decision-making concerning those to be accredited. For the understanding of the accreditation process, we modeled the demands management standard and developed the corresponding risk management matrix. In addition, we studied university specifications and conducted interviews with university officials on the basis of internal and external criteria that are essential for the training. These data will be presented and commented. For the evaluation of our proposal, we applied TOPSIS on a course sample.

\section{A. Model of Accreditation of Innovative University Courses}

The compliance with the standards and criteria stipulated by the National Agency for Evaluation and Insurance Quality of Higher Education and Scientific Research (ANEAQ) is essential for the acceptance of the training proposed by any institution. The following model presents the general process for the processing of accreditation requests for training and the main conditions to be taken into consideration in order to avoid the return of refusals or major revisions: at least 1 teacher per higher grade, the appropriate hourly volume in theory and practice as well as internships and partnerships to prepare profiles for the professional world as shown in Figure 2.

\section{B. Risk Management Matrix}

The interviewees unanimously expressed the usefulness of the designed risk management matrix which specifies not only the main risks to be considered, but also the responsibility and actions to be taken to make the decision effective. They have completed it and have judged that these risks are to be minimized or even avoided and must be taken into consideration before any training proposal (Table II). 


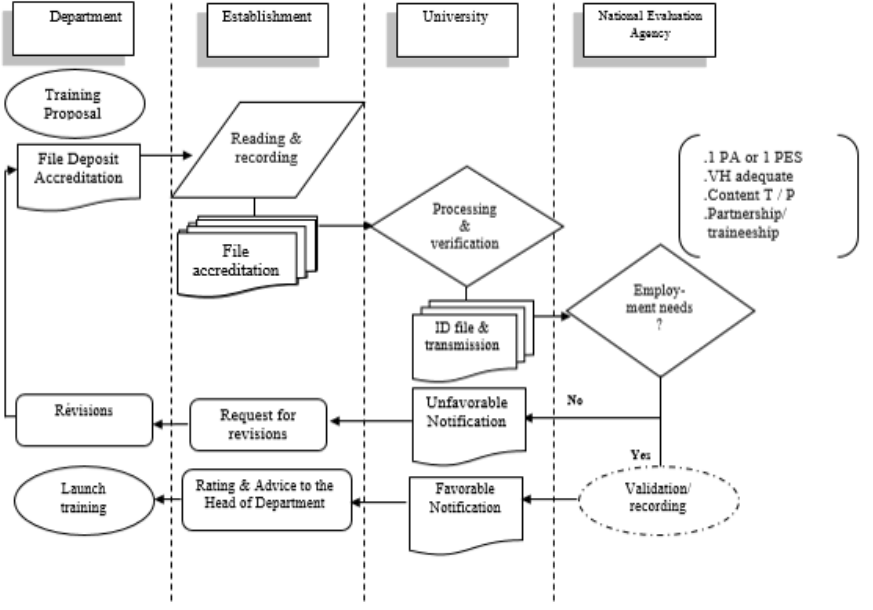

Fig. 2. Processing process for training accreditation applications

TABLE II. RISK MANAGEMENT MATRIX

\begin{tabular}{|c|c|c|c|c|c|}
\hline Risk & $\begin{array}{c}\text { Probability } \\
\text { rating }\end{array}$ & $\begin{array}{c}\text { Severity } \\
\text { rating }\end{array}$ & $\begin{array}{c}\text { Priority } \\
\text { rating }\end{array}$ & Responsibility & $\begin{array}{c}\text { Action to be } \\
\text { taken }\end{array}$ \\
\hline $\begin{array}{c}\text { Lack of } \\
\text { classrooms }\end{array}$ & $3 / 5$ & $4 / 5$ & $12 / 25$ & University & $\begin{array}{c}\text { Construction } \\
\text { Enlargement }\end{array}$ \\
\hline $\begin{array}{c}\text { Lack of } \\
\text { human } \\
\text { resources }\end{array}$ & $4 / 5$ & $4 / 5$ & $16 / 25$ & Establishment & $\begin{array}{c}\text { Continuing } \\
\text { Education } \\
\text { Session }\end{array}$ \\
\hline $\begin{array}{c}\text { Lack of } \\
\text { equipment }\end{array}$ & $4 / 5$ & $5 / 5$ & $20 / 25$ & $\begin{array}{c}\text { Establishment/ } \\
\text { University }\end{array}$ & Acquisition \\
\hline
\end{tabular}

The risk management matrix in Table II clearly shows that teaching resources and human resources are the most important according to their respective ratings of $20 / 25$ and $16 / 25$, which is explained by the risk of lack of rooms that can be solved by adequate automatized planning or an expansion of the establishment. Thus, the managers must establish a policy of continuous training of human resources permanently according to the evolution of the market and an adequate budgetary strategy relating to the educational equipment necessary for each department. To make the study relevant, we have defined, in addition to these indicators, internal and external criteria based on program specifications and interviewee responses.

\section{Internal and External Criteria}

Table III provides the main internal criteria of Moroccan university courses, the main objective of the departments is the adequacy of the proposals with the university strategy which aims to reach $100 \%$ in terms of innovation and development in order to meet the expectations of the market and encourage scientific research. Table III illustrates the results of the interviews based on the specifications and the actual estimate for each of the criteria according to the specifications. We were able to determine 7 internal and 3 external criteria. The internal ones are part of the school's strategy and are the key to the success of the existing training and future ones. Externally, these are the conditions to be respected for alignment with the standards put in place concerning requests for accreditation of new training. These criteria will allow university officials to detect, qualitatively and quantitatively, the defects and report on the improvement of the situation and good planning. In addition to the ratings in the risk management matrix and standards in the accreditation processing model, the vision will be clear in identifying priority areas for improvement to avoid inefficient decision-making. The external criteria are shown in Table IV and are complementing the internal ones in order to prepare competent profiles in adequacy with the socioeconomic status and respect for the ANEAQ standards. They concern especially the rank of human resources, the hourly amount and the content which must be theoretical and practical. Table IV shows that the partnership is essential and must be developed for all courses in order to gain knowledge of the market and easy integration in active life and internships. It is therefore necessary to maximize the agreements and partnerships with companies and administrations. Internal and external criteria, partnership and internships considerably influence the decision to be taken and constitute the key to evaluate existing training cards and launching new training. They will be implemented via TOPSIS in order to conclude with recommendations of interest for our universities.

TABLE III. MAIN INTERNAL CRITERIA

\begin{tabular}{|c|c|c|c|c|c|c|c|}
\hline Criteria & \multicolumn{2}{|c|}{ Motivation } & \multicolumn{2}{|c|}{ Human resources } & \multicolumn{2}{|c|}{ Technical resources } \\
\hline course & innovation & $\begin{array}{c}\text { market } \\
\text { needs }\end{array}$ & team & experience & $\begin{array}{c}\text { class- } \\
\text { rooms }\end{array}$ & $\begin{array}{c}\text { work- } \\
\text { shops }\end{array}$ & equipment \\
\hline BDCC & $95 \%$ & $95 \%$ & $50 \%$ & $100 \%$ & $65 \%$ & $30 \%$ & $40 \%$ \\
\hline GLSID & $90 \%$ & $80 \%$ & $65 \%$ & $90 \%$ & $65 \%$ & $40 \%$ & $45 \%$ \\
\hline MLI & $85 \%$ & $80 \%$ & $65 \%$ & $90 \%$ & $65 \%$ & $35 \%$ & $40 \%$ \\
\hline GMSI & $75 \%$ & $85 \%$ & $70 \%$ & $90 \%$ & $70 \%$ & $50 \%$ & $45 \%$ \\
\hline SID & $70 \%$ & $80 \%$ & $75 \%$ & $75 \%$ & $65 \%$ & $40 \%$ & $40 \%$ \\
\hline GECSI & $80 \%$ & $85 \%$ & $65 \%$ & $90 \%$ & $70 \%$ & $45 \%$ & $45 \%$ \\
\hline GMASI & $75 \%$ & $80 \%$ & $70 \%$ & $90 \%$ & $70 \%$ & $50 \%$ & $45 \%$ \\
\hline
\end{tabular}

TABLE IV. EXTERNAL CRITERIA

\begin{tabular}{|c|c|c|c|c|}
\hline \multicolumn{2}{|c|}{ Alignment with standards } & \multirow{2}{*}{ Partnership } & \multirow{2}{*}{ Traineeship } \\
\hline Grade & VH & Content & & Yes \\
\hline $2 \mathrm{PES}$ & $100 \%$ & $\mathrm{~T} / \mathrm{P}$ & Yes & Yes \\
\hline $3 \mathrm{PA}$ & $100 \%$ & $\mathrm{~T} / \mathrm{P}$ & Yes & Yes \\
\hline $2 \mathrm{PA}$ & $100 \%$ & $\mathrm{~T} / \mathrm{P}$ & Yes & Yes \\
\hline $1 \mathrm{PA}$ & $100 \%$ & $\mathrm{~T} / \mathrm{P}$ & Not yet & Yes \\
\hline $4 \mathrm{PA}$ & $100 \%$ & $\mathrm{~T} / \mathrm{P}$ & Not yet & Yes \\
\hline $3 \mathrm{PA}$ & $100 \%$ & $\mathrm{~T} / \mathrm{P}$ & Not yet & Yes \\
\hline $1 \mathrm{PA}$ & $100 \%$ & $\mathrm{~T} / \mathrm{P}$ & Yes & Yes \\
\hline $1 \mathrm{PA}$ & $100 \%$ & $\mathrm{~T} / \mathrm{P}$ & Not yet & \\
\hline
\end{tabular}

\section{TOPSIS Implementation}

After the identification of the alternatives and criteria, the results of our interviews will be implemented under the MCDM TOPSIS in order to identify the importance coefficients and prioritize the best decision. We will then calculate the weighted scores for each of the formations according to the standardized criteria and values in order to prioritize and optimize the different formations.

\section{1) Formation of Decision Matrix}

The choice of alternatives and criteria is the most important step in decision making. Indeed, selecting the key indicators is a basis that will allow university officials to prioritize and optimize actions for better management. The alternatives and criteria codes are presented in Figure 3.

\section{2) Formation of Weight Matrix}

In Table $\mathrm{V}$ we see the selected alternatives and the scoring 
of each alternative on different criteria. The dataset is used as decision matrix and then the normalized decision matrix is calculated (Table VI).

\begin{tabular}{|l|l|}
\hline Code & Alternatives \\
\hline A1 & BDCC \\
\hline A2 & GLSID \\
\hline A3 & MLI \\
\hline A4 & GMSI \\
\hline A5 & SID \\
\hline A6 & GECSI \\
\hline A7 & GMASI \\
\hline
\end{tabular}

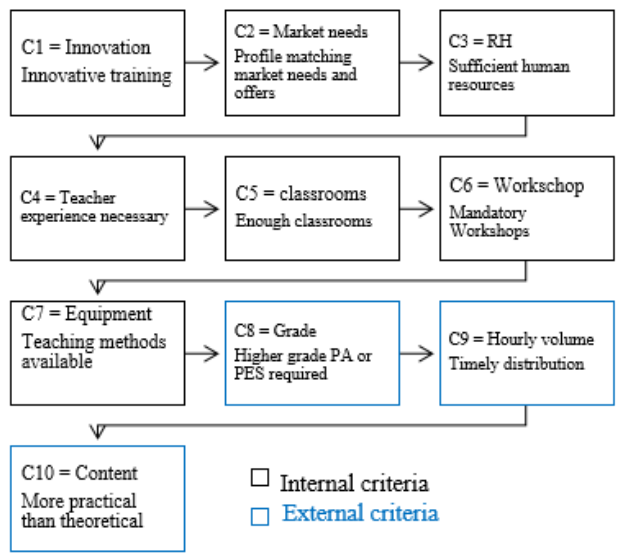

Fig. 3. Codification of internal and external criteria

TABLE V. WEIGHT MATRIX

\begin{tabular}{|c|c|c|c|c|c|c|c|c|c|c|}
\hline $\mathbf{a}_{\mathbf{i j}}$ & $\mathbf{C 1}$ & $\mathbf{C 2}$ & $\mathbf{C 3}$ & $\mathbf{C 4}$ & $\mathbf{C 5}$ & $\mathbf{C 6}$ & $\mathbf{C 7}$ & $\mathbf{C 8}$ & $\mathbf{C 9}$ & $\mathbf{C 1 0}$ \\
\hline $\mathbf{A 1}$ & 95 & 95 & 50 & 90 & 65 & 30 & 40 & 43 & 1 & 1 \\
\hline $\mathbf{A 2}$ & 95 & 100 & 65 & 100 & 80 & 80 & 45 & 43 & 1 & 1 \\
\hline $\mathbf{A 3}$ & 85 & 80 & 65 & 90 & 65 & 35 & 40 & 38 & 1 & 1 \\
\hline $\mathbf{A 4}$ & 75 & 85 & 70 & 90 & 70 & 50 & 45 & 38 & 0 & 1 \\
\hline $\mathbf{A 5}$ & 70 & 80 & 75 & 75 & 65 & 40 & 40 & 43 & 0 & 1 \\
\hline $\mathbf{A 6}$ & 80 & 85 & 65 & 80 & 70 & 45 & 45 & 26 & 0 & 1 \\
\hline $\mathbf{A 7}$ & 75 & 80 & 70 & 90 & 70 & 50 & 45 & 38 & 1 & 1 \\
\hline
\end{tabular}

3) Determination of Positive and Negative Ideal Solutions

Positive and negative ideal solutions, $A^{+}$and $A^{-}$are defined according to the normalized decision matrix (Table VII).

\section{4) Calculation of the Separation Measures}

For each competitive alternative the separation distance is calculated in Table VIII.

\section{5) Ratio Calculation}

The relative closeness of each location to TOPSIS ideal solution is measured in Table IX.

\section{6) Classify Actions}

The alternatives are ranked in decreasing order (Table X).

TABLE VI. PERFORMANCE RATING

\begin{tabular}{|c|c|c|c|c|c|c|c|c|c|c|}
\hline $\mathbf{R i j}$ & & & & & & & & & & \\
\hline A1 & 0.43 & 0.41 & 0.29 & 0.39 & 0.35 & 0.23 & 0.35 & 0.42 & 0.50 & 0.38 \\
\hline $\mathbf{A 2}$ & 0.43 & 0.44 & 0.37 & 0.43 & 0.44 & 0.61 & 0.40 & 0.42 & 0.50 & 0.38 \\
\hline A3 & 0.39 & 0.35 & 0.37 & 0.39 & 0.35 & 0.27 & 0.35 & 0.37 & 0.50 & 0.38 \\
\hline A4 & 0.34 & 0.37 & 0.40 & 0.39 & 0.38 & 0.38 & 0.40 & 0.37 & 0.00 & 0.38 \\
\hline A5 & 0.32 & 0.35 & 0.43 & 0.32 & 0.35 & 0.31 & 0.35 & 0.42 & 0.00 & 0.38 \\
\hline A6 & 0.37 & 0.37 & 0.37 & 0.34 & 0.38 & 0.34 & 0.40 & 0.25 & 0.00 & 0.38 \\
\hline A7 & 0.34 & 0.35 & 0.40 & 0.39 & 0.38 & 0.38 & 0.40 & 0.37 & 0.50 & 0.38 \\
\hline
\end{tabular}

TABLE VII. POSITIVE AND NEGATIVE IDEAL SOLUTIONS

\begin{tabular}{|c|c|c|c|c|c|c|c|c|c|c|}
\hline vmax A+ & 0.43 & 0.44 & 0.43 & 0.43 & 0.44 & 0.61 & 0.40 & 0.42 & 0.50 & 0.38 \\
\hline
\end{tabular} \begin{tabular}{|l|l|l|l|l|l|l|l|l|l|l|}
\hline vmin A- & 0.32 & 0.35 & 0.29 & 0.32 & 0.35 & 0.23 & 0.35 & 0.25 & 0.00 & 0.38 \\
\hline
\end{tabular}
TABLE VIII. SEPARATION MEASURES

\begin{tabular}{|c|c|c|}
\hline Course code & Smin & Smax \\
\hline $\mathbf{A 1}$ & 0.546676 & 0.420843 \\
\hline $\mathbf{A 2}$ & 0.686478 & 0.057166 \\
\hline $\mathbf{A 3}$ & 0.53037 & 0.379255 \\
\hline $\mathbf{A 4}$ & 0.240516 & 0.568416 \\
\hline $\mathbf{A 5}$ & 0.231595 & 0.61971 \\
\hline $\mathbf{A 6}$ & 0.161789 & 0.609396 \\
\hline $\mathbf{A 7}$ & 0.554413 & 0.276441 \\
\hline
\end{tabular}

TABLE IX. RATIO VALUES

\begin{tabular}{|c|c|c|}
\hline Course code & Coefficients & Ranking \\
\hline A1 & 0.923127 & 1 \\
\hline $\mathbf{A 2}$ & 0.667281 & 2 \\
\hline $\mathbf{A 3}$ & 0.583065 & 3 \\
\hline $\mathbf{A 4}$ & 0.565028 & 4 \\
\hline $\mathbf{A 5}$ & 0.297325 & 5 \\
\hline $\mathbf{A 6}$ & 0.272047 & 6 \\
\hline $\mathbf{A 7}$ & 0.209792 & 7 \\
\hline
\end{tabular}

TABLE $X . \quad$ RANKING VALUES

\begin{tabular}{|c|c|c|}
\hline Course & Coefficients & Ranking \\
\hline GLSID & 0.923127 & 1 \\
\hline GMASI & 0.667281 & 2 \\
\hline MLI & 0.583065 & 3 \\
\hline BDCC & 0.565028 & 4 \\
\hline GMSI & 0.297325 & 5 \\
\hline SID & 0.272047 & 6 \\
\hline GECSI & 0.209792 & 7 \\
\hline
\end{tabular}

\section{DISCUSSION}

Compensatory methods such as TOPSIS allow trade-offs between criteria, where a poor result in one criterion can be negated by a good result in another. It provides a more realistic form of modeling than non-compensatory methods. Using TOPSIS, the collected results respond to our problematic, which aims to innovate in the field of university training, whether initial or continuous, and above all to prioritize and optimize actions in order to remedy the difficulties encountered before, during and after the launch of a new course. Figure 4 illustrates the degree of prioritization of different courses according to the studied criteria.

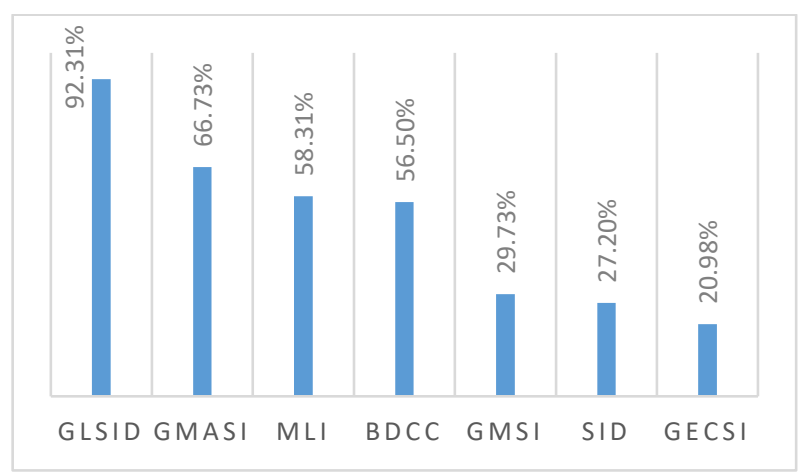

Fig. 4. Prioritization

The result of the proposed method shows that the first 4 courses are favored by several factors that can be summarized in: 


\section{- Relevant course modules}

- Interesting potential of human resources

- Strong demand for these specialties on the market

However, for all courses, we must focus on the material and teacher's specialties constraints. In addition, some modules may be enriched, deleted or replaced. The results show that the engineering, industry and big data rank first in relation to others because all criteria are fulfilled. This explains why, before launching a new course, we have to focus on the indicators studied and evaluate the limits of the human and material resources which are at the origin of the success of any course. In addition, we must prioritize these courses because they are innovative and meet current and immediate market expectations. Admittedly, they require more teaching resources and considerable experience in the field, but the situation can be improved by setting up performance tools such as balanced scorecards. Our method allowed the evaluation of possible alternative solutions for the continuous improvement of the performance of the studied formations. The proposed framework can help universities identify the strengths and weaknesses of their human and material resources. It also makes it easier for decision-makers to plan future strategies to develop educational courses and identify the best practices for each course while respecting current strategies, the job market, and the technological evolution.

\section{CONCLUSION}

The main goal of this study was to provide a decisionmaking tool for effective management of the initial and continuing training map. We focused on the case of multicriteria decision-making in the system of applications for accreditation of innovative training in order to prioritize decisions and the incessant changes in the labor market. It should be noted that the interaction between the different stakeholders (decision makers, department heads and teachers) is always present. In this context, we opted for MCDM methods in general and TOPSIS in particular, which uses precise parameters to calculate the performance for each studied element. Using this tool, we were able to quantify the internal and external criteria identified from specifications and interviews. These indicators were determined and can be expanded in the future according to the academic needs and standards. They allowed us to to enable decision-makers to target the best alternative and also to correct those that are interesting but have lower results. In conclusion, the multicriterion aspect and the proposed approach combining the analysis of internal/external criteria via the TOPSIS tool, made possible to select and prioritize the actions to be taken for an effective decision. These coefficients will help university officials in determining the value of different alternatives in order to focus human and material resources on the emergencies to be addressed and the innovative trainings to be planned. When it comes to future work, this same approach can be completed by a calculation of weights of each of the criteria announced or taken over with Fuzzy TOPSIS or PROMETHEE GAIA for more details, especially the management of uncertainties and sensitivity of situations through a prescriptive and descriptive approach, and scorecards for helping in decision-making.

\section{REFERENCES}

[1] M. Diaby, F. Valognes, A. Clement-Demange, "Utilisation d'une methode multicritere d'aide a la decision pour le choix des clones d'hevea a planter en Afrique", Biotechnologie, Agronomie, Societe et Environnement, Vol. 14, No. 2, pp. 299-309, 2010 (in French)

[2] D. Vanderpooten, Aide Multicritere a la Decision Concepts, Methodes et Perspectives, ENS Cachan, 2008 (in French)

[3] S. B. Mena, "Introduction aux methodes multicriteres d'aide a la decision", Biotechnologie, Agronomie, Societe et Environnement, Vol. 4, No. 2, pp. 83-93, 2000 (in French)

[4] J. Ninin, L. Mazeau, "La recherche operationnelle: De quelques enjeux juridiques des mecanismes d'aide a la decision", Lex Electronica, Vol. 22, pp. 57-79, 2017 (in French)

[5] D. C. Porumbel, "Algorithmes Heuristiques et Techniques d'Apprentissage - Applications au Probleme de Coloration de Graphe", PhD Thesis, Université d'Angers, 2009 (in French)

[6] B. Roy, Regard Historique sur la Place de la Recherche Operationnelle et de l'Aide a la Decision en France, Universite Paris-Dauphine, 2006 (in French)

[7] T. L. Saaty, "Decision making with the analytic hierarchy process", International Journal of Services Sciences, Vol. 1, No. 1, pp. 83-98, 2008

[8] B. Roy, H. Aissi, Robustesse en Aide Multicritere a la Decision, Universite Paris-Dauphine 2008 (in French)

[9] A. Appriou, "Methodologie de la gestion intelligente des senseurs", Traitement du Signal, Vol. 22, No. 4, pp. 305-306, 2005 (in French)

[10] B. Roy, D. Bouyssou, Aide Multicritere a la Decision: Methodes et Cas, Economica, 1993 (in French)

[11] M. Hanine, O. Boutkhoum, A. Tikniouine, T. Agouti, "Application of an integrated multi-criteria decision making AHP-TOPSIS methodology for ETL software selection", Springerplus, Vol. 5, pp. 1-17, 2016

[12] T. L. Saaty, L. G. Vargas, Models, Methods, Concepts \& Applications of the Analytic Hierarchy Process, Springer, 2001

[13] F. Tscheikner-Gratl, P. Egger, W. Rauch, M. Kleidorfer, "Comparison of Multi-Criteria Decision Support Methods for Integrated Rehabilitation Prioritization”, Water, Vol. 9, No. 2, pp. 1-28, 2017

[14] D. Ozturk, F. Batuk, "Technique for order preference by similarity to ideal solution (topsis) for spatial decision problems", ISPRS 4th International Workshop, Trento, Italy, March 2-4, 2011

[15] A. Mardani, A. Jusoh, K. Nor, Z. Khalifah, N. Zakwan, Alireza, "Multiple criteria decision-making techniques and their applications", Economic Research-Ekonomska Istrazivanja, Vol. 28, No. 1, pp. 516571,2015

[16] T. Jolanta, Z. Edmundas, T. Zenonas, P. Vainiunas, "Multi-criteria complex for profitability analysis of construction projects", Economics and Management, Vol. 16, pp. 969-973, 2011

[17] Z. Edmundas, M. Abbas, T. Zenonas, J. Ahmad, N. Khalil, "Development of TOPSIS method to solve complicated decision-making problems", International Journal of Information Technology \& Decision Making, Vol. 15, No. 3, pp. 645-682, 2016

[18] G. O. Odu, O. E. Charles-Owaba, "Review of Multi-criteria Optimization Methods - Theory and Applications", IOSR Journal of Engineering, Vol. 3, No. 10, pp. 1-14, 2013

[19] D. Ayadi, Optimisation Multicritere de la Fiabilite: Application du Modele de Goal Programming Avec les Fonctions de Satisfactions dans l'Industrie de Traitement de Gaz, PhD Thesis, Universite d'Angers, 2010 (in French)

[20] K. Solecka, "ELECTRE III method in assessment of variants of integrated urban public transport system in Cracow", Transport Problems: an International Scientific Journal, Vol. 9, No. 4, pp. 83-96, 2014 
[21] L. Sifeng, C. Hua, C. Ying, Y. Yingjie, "Advance in grey incidence analysis modelling", 2011 IEEE International Conference on Systems, Man, and Cybernetics, Anchorage, USA, October 9-12, 2011

[22] F. Y. Ma, "Analysis of energy effinciency operational indicator of bulk carrier operational data using gray relation method", Journal of Oceanography and Marine Science, Vol. 5, No. 4, pp. 30-36, 2014

[23] S. Greco, M. Ehrgott, J. R. Figueira, Multiple Criteria Decision Analysis: State of the Art Surveys, Springer, 2005

[24] S. C. Deshmukh, "Preference Ranking Organization Method Of Enrichment Evaluation Promethee", International Journal of Engineering Science Invention, Vol. 2, No. 11, pp. 28-34, 2013

[25] M. Zare, C. Pahl, H. Rahnama, M. Nilashi, A. Mardani, O. Ibrahim, H. Ahmadi, "Multi-criteria decision making approach in E-learning: A systematic review and classification", Applied Soft Computing, Vol. 45, pp. 108-128, 2016 